\section{Commentary: Thoracic endovascular aortic arch repair using custom made endografts: $A$ good alternative to open repair?}

\author{
Wael Ahmad, MD, ${ }^{\mathrm{a}}$ and Oliver J. Liakopoulos, $\mathrm{MD}^{\mathrm{b}}$
}

Since its introduction in the 1990s, the frozen elephant trunk (FET) technique has provided an excellent approach to treating various pathologies of the aortic arch. ${ }^{1}$ Therefore, current guidelines of the European Society of Cardiology and the Vascular Domain of the European Association of Cardiothoracic Surgery, as well as the expert consensus document of European Association of Cardiothoracic Surgery and the European Society for Vascular Surgery, univocally recommend the FET technique for treating various arch pathologies. ${ }^{2,3}$

However, the invasive nature of open aortic arch repair, which is still considered the gold standard, especially in patients who are unfit for open surgery, paved the way for less invasive endovascular procedures, including hybrid arch repair (supra-aortic debranching plus endovascular treatment) and even total endovascular arch repair. The concept of a total endovascular aortic arch repair using custommade devices (CMDs), as well as the chimney graft or parallel graft technique in addition to in situ fenestration, is progressively consolidating its place as an acceptable alternative to treat the aortic arch in selected patients. ${ }^{4,5}$

In general, there are 2 types of CMDs: branched and fenestrated. An obvious disadvantage of CMDs is the long

From the a Department of Vascular and Endovascular Surgery, University Hospital of Cologne, Cologne, Germany; and ${ }^{b}$ Department of Cardiac Surgery, KerckhoffClinic Bad Nauheim, Campus Kerckhoff, University of Giessen, Giessen, Germany.

Disclosures: The authors reported no conflicts of interest.

The Journal policy requires editors and reviewers to disclose conflicts of interest and to decline handling or reviewing manuscripts for which they may have a conflict of interest. The editors and reviewers of this article have no conflicts of interest.

Received for publication Sept 29, 2020; revisions received Sept 29, 2020; accepted for publication Oct 1, 2020; available ahead of print Oct 10, 2020.

Address for reprints: Oliver J. Liakopoulos, MD, Department of Cardiac Surgery, Kerckhoff-Clinic Bad Nauheim, Campus Kerckhoff, University of Giessen, Benekestr 2-8, 61231 Bad Nauheim, Germany (E-mail: o.liakopoulos@ kerckhoff-klinik.de).

JTCVS Techniques 2020;4:26-7

2666-2507

Copyright (c) 2020 The Authors. Published by Elsevier Inc. on behalf of The American Association for Thoracic Surgery. This is an open access article under the CC BY-NCND license (http://creativecommons.org/licenses/by-nc-nd/4.0/).

https://doi.org/10.1016/j.xjtc.2020.10.003

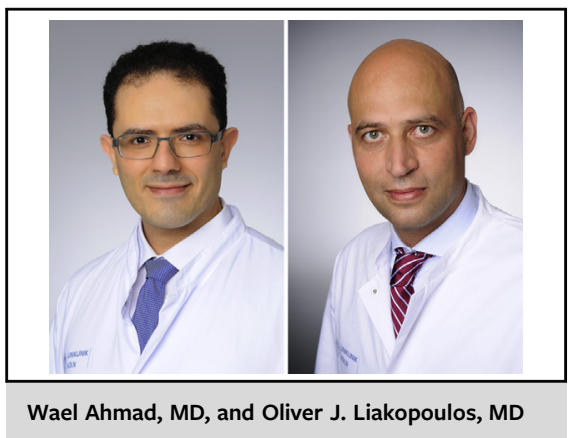

CENTRAL MESSAGE

Total endovascular repair of the aortic arch using a branched stent graft is presented as an acceptable alternative to conventional open arch repair techniques.

production period (approximately 4 to 8 weeks), which makes the implementation of these grafts in urgent situations limited. This issue can be addressed by parallel grafts, which are readily available off the shelf and at lower cost, but with a higher risk of type I endoleak (ie, gutter endoleak). Nevertheless, the design of CMDs using innerbranches will facilitate the future production of these devices as off-the-shelf CMDs.

In a large study from Japan reporting 363 patients undergoing total endovascular arch repair with the fenestrated CMD "Najuta" stent graft, 30-day mortality and stroke rate were exceptionally low, at $1.6 \%$ and $1.8 \%$, respectively. ${ }^{6}$ In contrast, 2 European studies with much smaller patient cohorts reported 0 to $5.5 \%$ mortality and a $5.5 \%$ to $11.1 \%$ stroke rate in 27 and 54 patients, respectively. ${ }^{7,8}$

In comparison, pooled estimates of 30-day mortality and stroke rate in 373 patients treated with chimney grafts for arch diseases were $8 \%$ and $3 \%$, respectively. ${ }^{4}$ A recently published study from our institution showed an estimated mean survival of 71.8 months (SE, 7.5; 95\% CI, 57.1 to 86.4 months) in elective endovascular procedures using chimney grafts in the aortic arch. ${ }^{9}$

In this issue of the Journal, Kudo and colleagues ${ }^{10}$ report their institutional experience of 28 patients with aortic arch pathologies $(79 \%$ degenerative aneurysms, $21 \%$ aortic dissections), and who were at high risk for conventional open surgery or aortocervical bypass surgery (debranching). ${ }^{10}$ The Bolton CMD with inner branches was used for aortic 
arch repair. No 30-day mortality was reported, and 4 patients $(14.3 \%)$ had a perioperative cerebrovascular event, with 2 disabling strokes. All patients with strokes had an atheroma grade $\geq 2$ in the brachiocephalic artery. The use of a protection device in the carotid arteries in approximately $36 \%$ of patients provided no additional benefit. Furthermore, the authors reported good mid-term cumulative survival rates of $92.7 \%$ at 1 year, $85.6 \%$ at 3 years, and $80.8 \%$ at 5 years.

Despite the relatively small study size, as well as the limited follow-up period, this study provides additional clinical evidence for the feasibility and safety of total endovascular aortic arch repair using branched CMDs in selected patients not amenable to conventional surgery. However, an important issue that needs to be addressed in future studies is the elevated stroke rates observed during endovascular procedures. Thus, meticulous selection of patients (no shaggy aorta or, as suggested by the authors, no atheroma grade $>2$ ) and further evolution of techniques (protection devices or endovascular devices) is needed to further improve the clinical results.

\section{References}

1. Hagl C, Pichlmaier M, Khaladj N. Elephant trunks in aortic surgery: fresh and frozen. J Thorac Cardiovasc Surg. 2013;145(suppl):S98-102.
2. Czerny M, Schmidli J, Adler S, van den Berg JC, Bertoglio L, Carrel T, et al. Current options and recommendations for the treatment of thoracic aortic pathologies involving the aortic arch: an expert consensus document of the European Association for Cardio-Thoracic surgery (EACTS) and the European Society for Vascular Surgery (ESVS). Eur J Cardiothorac Surg. 2019;55: 133-62.

3. Shrestha M, Bachet J, Bavaria J, Carrel TP, De Paulis R, Di Bartolomeo R, et al. Current status and recommendations for use of the frozen elephant trunk technique: a position paper by the Vascular Domain of EACTS. Eur J Cardiothorac Surg. 2015;47:759-69.

4. Ahmad W, Mylonas S, Majd P, Brunkwall JS. A current systematic evaluation and meta-analysis of chimney graft technology in aortic arch diseases. J Vasc Surg. 2017;66:1602-10.e2.

5. Haulon S, Greenberg RK, Spear R, Eagleton M, Abraham C, Lioupis C, et al. Global experience with an inner branched arch endograft. J Thorac Cardiovasc Surg. 2014;148:1709-16.

6. Yokoi Y, Azuma T, Yamazaki K. Advantage of a precurved fenestrated endograft for aortic arch disease: simplified arch aneurysm treatment in Japan 2010 and 2011. J Thorac Cardiovasc Surg. 2013;145(suppl):S103-9.

7. Spear R, Haulon S, Ohki T, Tsilimparis N, Kanaoka Y, Milne CPE, et al. Editor's choice - Subsequent results for arch aneurysm repair with inner branched endografts. Eur J Vasc Endovasc Surg. 2016;51:380-5.

8. Tsilimparis N, Detter C, Law Y, Rohlffs F, Heidemann F, Brickwedel J, et al. Single-center experience with an inner branched arch endograft. J Vasc Surg. 2019; 69:977-85.e1.

9. Ahmad W, Liakopoulos OJ, Mylonas S, Wegner M, Brunkwall J, Dorweiler B Long-term outcomes after thoracic endovascular aortic repair using chimneygrafts for aortic arch pathologies: 10 Years of single-center experience. Ann Vasc Surg. September 12, 2020 [Epub ahead of print].

10. Kudo T, Kuratani T, Shimamaru K, Sawa Y. Early and mid-term results of thoracic endovascular aortic repair using a branched endograft for aortic arch pathologies: a retrospective single-center study. J Thorac Cardiovasc Surg Tech. 2020;4:17-25. 